\title{
TRACKING DRIVER EYE MOVEMENTS AT PERMISSIVE LEFT-TURNS
}

\author{
Michael A. Knodler Jr. \\ Department of Civil \& Environmental Engineering \\ University of Massachusetts - Amherst \\ Amherst, Massachusetts, USA \\ E-mail: mknodler@ecs.umass.edu \\ David A. Noyce \\ Department of Civil \& Environmental Engineering \\ University of Wisconsin - Madison \\ Madison, Wisconsin, USA \\ E-mail: noyce@engr.wisc.edu
}

\begin{abstract}
Summary: The objective of this analysis was to identify sources of information used by left-turning drivers. To complete the experiment, a virtual network of signalized intersections was created for use in a driving simulator equipped with head and eye tracking equipment. Fourteen drivers were recruited to participate in the experiment, which included two independent variables (permissive signal indication and presence of opposing traffic). The primary dependent variable was the associated eye movements at permissive left-turns, including the magnitude of time focused on each potential cue and the pattern in which cues were detected. To complete the analysis, eye movements were tracked and the screen was divided into "areas of interest," which coincided with potential cues used in the completion of a permissive left turn. For each permissive scenario, drivers used more total cues when no opposing traffic was present. Specifically, in the absence of opposing traffic, drivers fixated on a wider array of available information. When opposing traffic was present, drivers spent a majority of time focused on opposing traffic and would use this as a base point from which they would glance at other data sources. Overall, drivers looked at least once at the protected/permissive left-turn (PPLT) signal display and the opposing traffic stream. Drivers tended to scan the intersection from right to left, after initially locating the PPLT signal display and opposing traffic and/or stop bar area. The results of the eye movement analysis are consistent with data obtained in a follow-up static evaluation.
\end{abstract}

\section{INTRODUCTION}

Improving the safety of the traveling public has been a consideration in the design and operation of transportation facilities for many years. Nevertheless, the desire to improve the capacity of our roadway system to accommodate the rapidly growing traffic volumes often outweighs the sometimes conflicting safety improvements. Arguably the most difficult maneuver for both traffic engineers and drivers is simultaneous movements that cross paths, specifically, left-turn movements. Driver confusion in and around the more than 300,000 signalized intersections in the United States is responsible for an increase in both delay and crash potential. In an attempt to safely and efficiently accommodate left-turning vehicles at signalized intersections protected/permissive left-turn (PPLT) signal phasing was developed. 
PPLT signal phasing provides a protected phase for left-turns, as well as a permissive phase during which left-turns can be made if gaps in opposing through traffic allow, all within the same signal cycle (Noyce 1998). Conceptually, PPLT signal phasing minimizes the protected left-turn phase time requirements while increasing the opportunity for left-turn maneuvers. Use of PPLT phasing can lead to increased left-turn capacity and reduced delay, while maintaining a desired level of safety. Nevertheless, the potential benefits associated with PPLT signal phasing can only be realized if the traffic control information is successfully communicated to and comprehended by the driver.

The recently completed National Cooperative Highway Research Program (NCHRP) Report 493 was a comprehensive, national research study to evaluate the operational advantages and safety aspects of various left-turn controls at signalized intersections, and was based upon several identified problems (Brehmer, 2003). The recurring major issue is related to the permissive phase when left-turning drivers are required to first yield, then select an adequate gap in the opposing traffic stream. The completion of this permissive left-turn maneuver necessitates that drivers complete a minimum of two independent tasks: (1) detect and process the left-turn signal indication, and (2) make the appropriate decision based upon the presence of opposing vehicles. This series of tasks can vary in complexity across intersections and is of concern because of the inherent potential for increased crashes and delay at permissive left-turns. Although the NCHRP Report 493 research included a comprehensive analysis of driver comprehension of the existing circular green permissive (CG) indication, and several alternatives including a flashing yellow arrow (FYA) and combined CG/FYA, there remains a need to evaluate the process and cues used by drivers in the completion of a permissive left-turn.

\section{PROBLEM STATEMENT}

Several research studies have found the left-turn signal indication to be only one of several cues drivers use when completing a permissive left-turn maneuver (Brehmer, 2003; Knodler, 2005). As a result, driver comprehension and the action that follows is in part based upon several potential cues. Despite the comprehensive driver comprehension experiments completed in previous research, there is still a need to assess the procedure by which drivers complete a permissive left-turn maneuver. More specifically, there is a need to identify what information drivers use, to what degree they use it, and the significance of the information in decision making when completing a left-turn maneuver.

The primary objectives of this research effort were to develop a driving simulator and eye tracking experiment to determine the feasibility of using these technologies for assessing driver behavior at permissive left-turns and to determine if an identifiable set of cues and corresponding scan pattern exists that drivers use to complete a permissive left-turn maneuver. This involves an understanding of the visual search pattern and the amount of time drivers use each visual cue. The underlying hypothesis is that the time on cue is a surrogate measure assumed to be proportional to its importance in information gathering. Furthermore, the identification of drivers' search procedures would likely provide valuable information about their comprehension of the PPLT signal display and other pieces of information that are critical to left-turn decisions. 


\section{EXPERIMENTAL METHODOLOGY}

To complete the experiment, a virtual network of signalized intersections was created for use in the Human Performance Laboratory (HPL) at the University of Massachusetts - Amherst. Fourteen drivers were recruited to participate in the experiment, which included two primary independent variables, including the permissive left-turn signal indication and the presence of opposing traffic. The primary dependent variable was the associated eye movements at permissive left-turns, including the magnitude of time focused on each potential cue and the pattern in which cues were detected.

\section{Human Performance Laboratory Equipment}

The UMass driving simulator is a full-scale, fixed-base, fully interactive dynamic driving simulator. The vehicle base of the driving simulator is a 1995 four-door Saturn Sedan. Simulator features are consistent with current model year vehicles. Drivers are capable of controlling the steering, braking, and accelerating similar to the actual driving process; the visual roadway adjusts accordingly to the driver's actions. The HPL driving simulator is pictured in Figure 1 (left) along with a screen capture of the simulated driving environment (right). The ASL Series 5000 eye tracker with head mounted optics was used. This unit allows the participant's head a full range of motion, and converts eye position to external point of gaze by superimposing cross hairs upon a video of the scene that is being viewed by the subject.
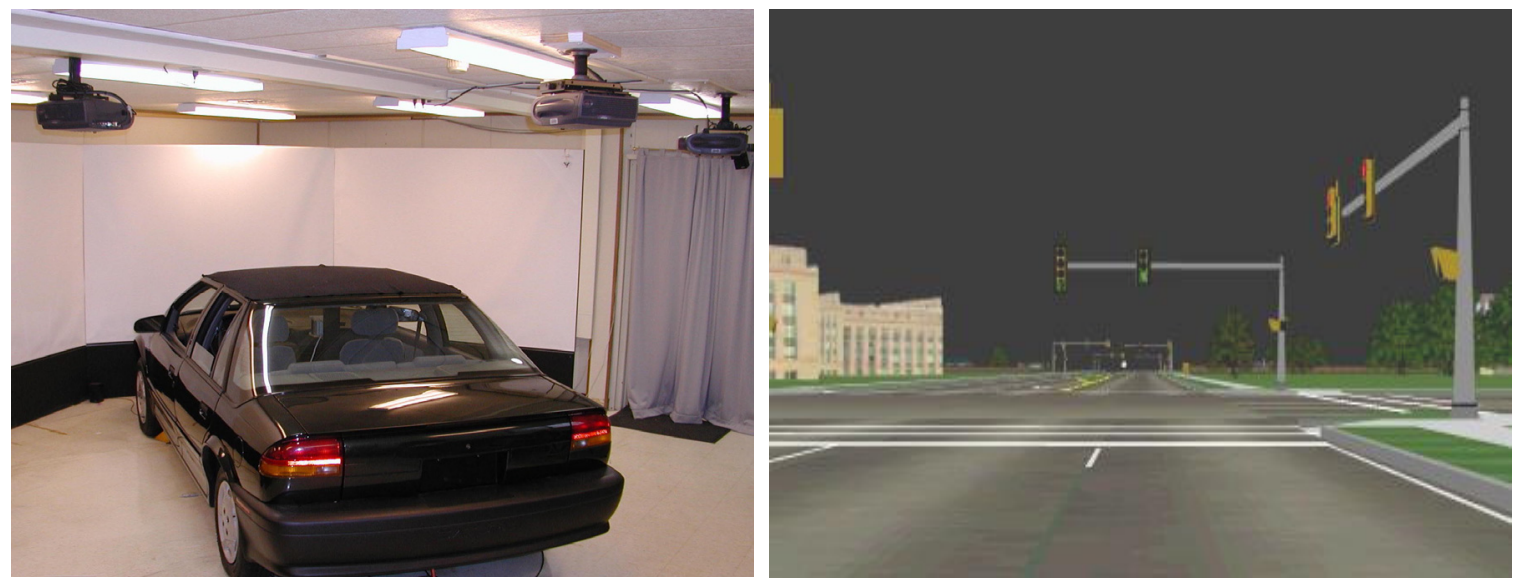

Figure 1. Human Performance Lab driving simulator at UMass

\section{Simulated Environment and Operations}

The three permissive left-turn signal indications tested included the circular green (current MUTCD standard), a flashing yellow arrow (recommended by NCHRP Report 493), and a combined circular green/flashing yellow arrow permissive indication, as pictured in Figure 2 . Drivers traversed a single driving module, consisting of 14 total intersections, six of which involved permissive left-turn maneuvers. Multiple start positions were used to provide appropriate counterbalancing and assure that each PPLT scenario was equally likely to be presented first to drivers. The rational for including additional intersections requiring drivers to 
complete a protected left-turn maneuver, proceed straight, or turn right provided experimental variability and reduced the probability of drivers keying in on the nature of the evaluation.

The operational characteristics within the simulation were relatively consistent at all intersections requiring drivers to complete a left turn. All experimental signal displays within the simulation rested in red (circular or arrow) as drivers approached the intersection. The signal displays then changed to the test indications once the driver was approximately 30 meters from the intersection stop bar.

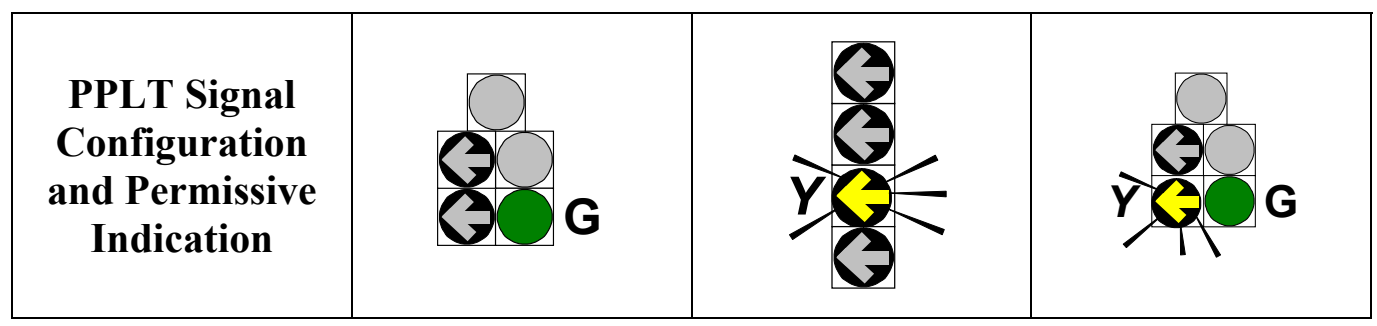

Figure 2. Experimental permissive indications

As noted, the presence of opposing vehicles was considered as one of the independent variables. Half of the six experimental (permissive left-turns) contained opposing traffic, which when present, was applied in a consistent format. The opposing traffic required drivers to simultaneously evaluate the PPLT signal display, traffic movement, and opposing gaps to complete a safe permissive left-turn maneuver. This methodology replicates the decision process required during actual operation of a motor vehicle within the roadway system, and was intended to provide insight regarding the cues drivers' use during the completion of a permissive left-turn maneuver. Six opposing vehicles were used to create the opposing traffic. Two vehicles were always positioned at the stop bar in the two through lanes opposing the left-turn driver. The remaining four vehicles were positioned further upstream in a specified gap sequence. Gaps between vehicles were set at three and seven seconds in a series of 7-3-7-7; therefore, opposing vehicles crossed the intersection seven, 10, 17, and 24 seconds behind the two initially queued opposing vehicles. Providing a consistent sequence of three and seven second gaps prevented gap selection from being a significant variable in the PPLT analysis.

\section{Method of Analysis}

The initial analysis for each of the six experimental intersections was the driver response. Although this information was useful, the more compelling data was related to the driver eye movements. To complete the analysis, eye movements were tracked and the screen was divided into "areas of interest," which coincided with potential cues used in the completion of a permissive left. A sample of the segmented driving simulator environment is presented in Figure 3. For the experimental scenarios in this evaluation, six areas of interest were considered as follows:

- PPLT signal display - the left turn signal head, which was either a five-section cluster or four-section vertical located over the lane line between the left-turn lane and adjacent through lane or centered over the left-turn lane; 
- Adjacent through signal - the adjacent three section signal head(s) located over the adjacent through lanes;

- Cross traffic - path of vehicles that would be followed by vehicles entering the intersection from the left-turn driver's right side;

- Opposing vehicles or opposing stop bar area - the opposite side of the intersection from the left-turn driver with either opposing vehicles or open lanes;

- Opposing intersection corner - the area on the far side of the intersection and to the left of the driver. This location includes the area where a pedestrian that may possibly cross the left-turn drivers path could be located; and

- Path of travel - in this instance represents the lanes in which the driver will be completing the left-turn. Specifically the lanes perpendicular and to the left of a driver waiting to complete a turn.

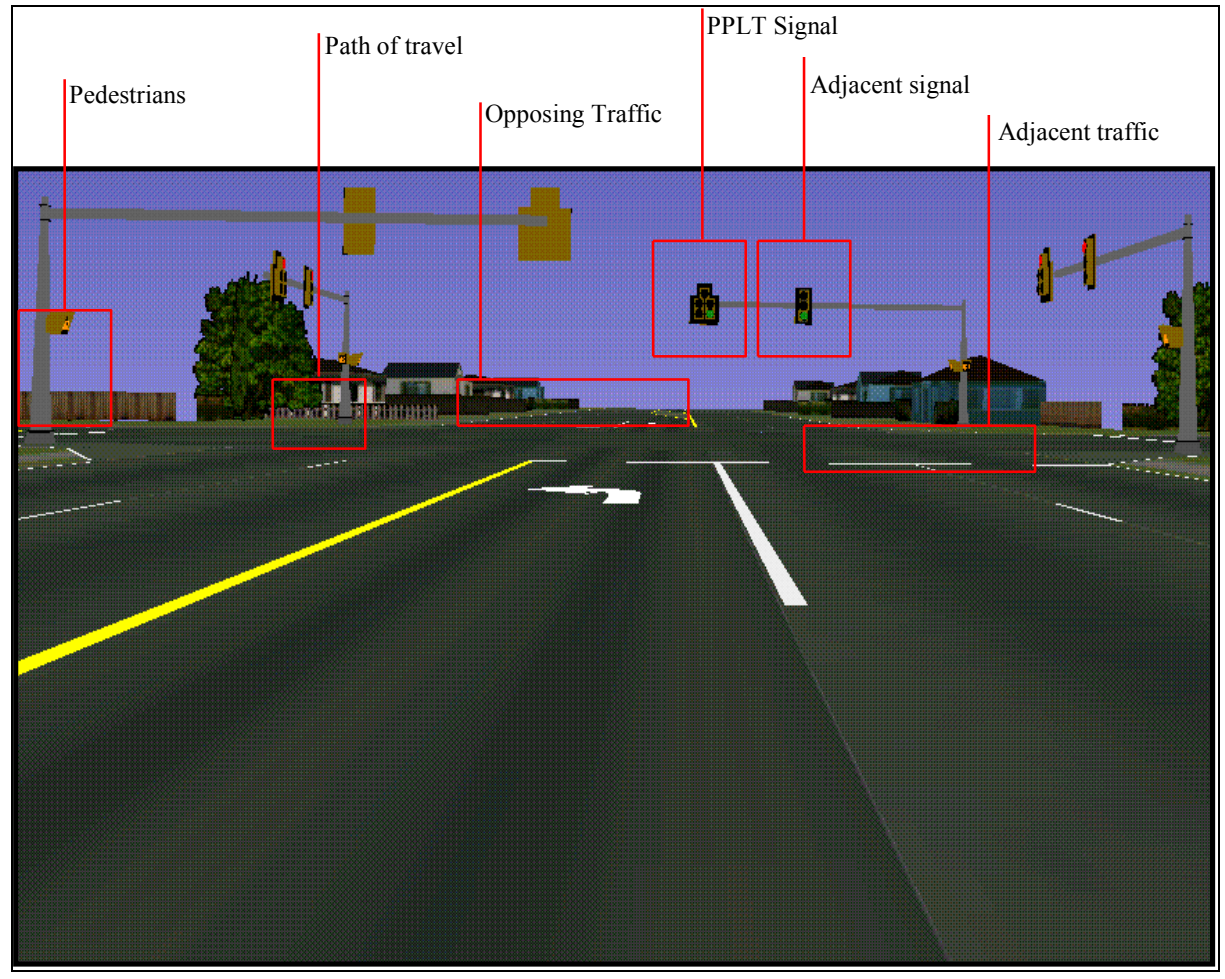

Figure 3. Sample of segmented areas of interest in simulated environment

\section{Results}

Although 14 drivers were initially recruited, three drivers were unable to complete the experiment due to complications with establishing accurate eye movement data. Nevertheless, the remaining 11 drivers navigated a single driving module, resulting in 66 experimental intersections evaluated. A detailed overview of driver eye movements was completed for each driver at each scenario in accordance with the segmented areas of interest defined. For reporting purposes, driver eye movements were classified in two ways: drivers who fixated on an area of interest for approximately one second or longer were said to have "focused" on that object, while driver fixations less than one second were classified as a "glance." Table 1 summarizes the cues 
used by each driver for each experimental display. A cue was considered used if the driver identified the area of interest at least once during their scan sequence.

Table 1. Summary of cues used (indicated by at least one glance)

\begin{tabular}{|c|c|c|c|c|c|c|c|}
\hline Driver & Area of Interest & $\begin{array}{c}\text { CG with } \\
\text { Traffic }\end{array}$ & $\begin{array}{l}\text { CG with } \\
\text { No Traffic }\end{array}$ & $\begin{array}{c}\text { CG/FYA } \\
\text { with } \\
\text { Traffic }\end{array}$ & $\begin{array}{c}\text { CG/FYA } \\
\text { with No } \\
\text { Traffic }\end{array}$ & $\begin{array}{c}\text { FYA with } \\
\text { Traffic }\end{array}$ & $\begin{array}{l}\text { FYA with } \\
\text { No Traffic }\end{array}$ \\
\hline \multirow{6}{*}{1} & PPLT Signal & $\mathrm{X}$ & $\mathrm{X}$ & $\mathrm{X}$ & $\mathrm{X}$ & $\mathrm{X}$ & $\mathrm{X}$ \\
\hline & Opp. Vehicles & $\mathrm{X}$ & $\mathrm{X}$ & $\mathrm{X}$ & $\mathrm{X}$ & $\mathrm{X}$ & $\mathrm{X}$ \\
\hline & Adj. Signal & & & & $\mathrm{X}$ & $\mathrm{X}$ & \\
\hline & Cross Traffic & & $\mathrm{X}$ & & & & $\mathrm{X}$ \\
\hline & Opp. Int. Corner & & & & $\mathrm{X}$ & & \\
\hline & Path of Travel & $\mathrm{X}$ & $\mathrm{X}$ & & $\mathrm{X}$ & & \\
\hline \multirow{6}{*}{2} & PPLT Signal & $\mathrm{X}$ & $\mathrm{X}$ & $\mathrm{X}$ & $\mathrm{X}$ & $\mathrm{X}$ & $\mathrm{X}$ \\
\hline & Opp. Vehicles & $\mathrm{X}$ & $\mathrm{X}$ & $\mathrm{X}$ & $\mathrm{X}$ & $\mathrm{X}$ & $\mathrm{X}$ \\
\hline & Adj. Signal & $\mathrm{X}$ & & & & & \\
\hline & Cross Traffic & & & & & & $\mathrm{X}$ \\
\hline & Opp. Int. Corner & & & & & & $\mathrm{X}$ \\
\hline & Path of Travel & & $\mathrm{X}$ & & $\mathrm{X}$ & $\mathrm{X}$ & $\mathrm{X}$ \\
\hline \multirow{6}{*}{3} & PPLT Signal & $\mathrm{X}$ & $\mathrm{X}$ & $\mathrm{X}$ & $\mathrm{X}$ & $\mathrm{X}$ & $\mathrm{X}$ \\
\hline & Opp. Vehicles & $\mathrm{X}$ & $\mathrm{X}$ & $\mathrm{X}$ & $\mathrm{X}$ & $\mathrm{X}$ & $\mathrm{X}$ \\
\hline & Adj. Signal & & $\mathrm{X}$ & $\mathrm{X}$ & $\mathrm{X}$ & & \\
\hline & Cross Traffic & & & & & & \\
\hline & Opp. Int. Corner & & & & & & \\
\hline & Path of Travel & $\mathrm{X}$ & & & & & $\mathrm{X}$ \\
\hline \multirow{6}{*}{4} & PPLT Signal & $\mathrm{X}$ & $\mathrm{X}$ & $\mathrm{X}$ & $\mathrm{X}$ & $\mathrm{X}$ & $\mathrm{X}$ \\
\hline & Opp. Vehicles & $\mathrm{X}$ & $\mathrm{X}$ & $\mathrm{X}$ & $\mathrm{X}$ & $\mathrm{X}$ & $\mathrm{X}$ \\
\hline & Adj. Signal & & & & & & \\
\hline & Cross Traffic & & & & & & \\
\hline & Opp. Int. Corner & & & & $\mathrm{X}$ & & $\mathrm{X}$ \\
\hline & Path of Travel & $\mathrm{X}$ & $\mathrm{X}$ & $\mathrm{X}$ & $\mathrm{X}$ & & $\mathrm{X}$ \\
\hline \multirow{6}{*}{5} & PPLT Signal & $\mathrm{X}$ & $\mathrm{X}$ & $\mathrm{X}$ & $\mathrm{X}$ & $\mathrm{X}$ & $\mathrm{X}$ \\
\hline & Opp. Vehicles & $\mathrm{X}$ & $\mathrm{X}$ & $\mathrm{X}$ & $\mathrm{X}$ & $\mathrm{X}$ & $\mathrm{X}$ \\
\hline & Adj. Signal & & & & & & \\
\hline & Cross Traffic & & & & & & \\
\hline & Opp. Int. Corner & & & & & & \\
\hline & Path of Travel & $\mathrm{X}$ & $\mathrm{X}$ & & $\mathrm{X}$ & & $\mathrm{X}$ \\
\hline \multirow{6}{*}{6} & PPLT Signal & $\mathrm{X}$ & $\mathrm{X}$ & $\mathrm{X}$ & $\mathrm{X}$ & $\mathrm{X}$ & $\mathrm{X}$ \\
\hline & Opp. Vehicles & $\mathrm{X}$ & $\mathrm{X}$ & $\mathrm{X}$ & $\mathrm{X}$ & $\mathrm{X}$ & $\mathrm{X}$ \\
\hline & Adj. Signal & $\mathrm{X}$ & $\mathrm{X}$ & & & $\mathrm{X}$ & $\mathrm{X}$ \\
\hline & Cross Traffic & & $X$ & & & & \\
\hline & Opp. Int. Corner & & & & & & \\
\hline & Path of Travel & & $\mathrm{X}$ & & & & $\mathrm{X}$ \\
\hline
\end{tabular}




\begin{tabular}{|c|c|c|c|c|c|c|c|}
\hline Driver & Area of Interest & $\begin{array}{c}\text { CG with } \\
\text { Traffic }\end{array}$ & $\begin{array}{l}\text { CG with } \\
\text { No Traffic }\end{array}$ & $\begin{array}{c}\text { CG/FYA } \\
\text { with } \\
\text { Traffic }\end{array}$ & $\begin{array}{c}\text { CG/FYA } \\
\text { with No } \\
\text { Traffic }\end{array}$ & $\begin{array}{c}\text { FYA with } \\
\text { Traffic }\end{array}$ & $\begin{array}{l}\text { FYA with } \\
\text { No Traffic }\end{array}$ \\
\hline \multirow{6}{*}{7} & PPLT Signal & $\mathrm{X}$ & $\mathrm{X}$ & $\mathrm{X}$ & $\mathrm{X}$ & $\mathrm{X}$ & $\mathrm{X}$ \\
\hline & Opp. Vehicles & $\mathrm{X}$ & $\mathrm{X}$ & $\mathrm{X}$ & $\mathrm{X}$ & $\mathrm{X}$ & $\mathrm{X}$ \\
\hline & Adj. Signal & & & & $\mathrm{X}$ & $\mathrm{X}$ & \\
\hline & Cross Traffic & & & & & & $\mathrm{X}$ \\
\hline & Opp. Int. Corner & & & & & & \\
\hline & Path of Travel & & $\mathrm{X}$ & & & & $\mathrm{X}$ \\
\hline \multirow{6}{*}{8} & PPLT Signal & $\mathrm{X}$ & $\mathrm{X}$ & $\mathrm{X}$ & $\mathrm{X}$ & $\mathrm{X}$ & $\mathrm{X}$ \\
\hline & Opp. Vehicles & $\mathrm{X}$ & $\mathrm{X}$ & $\mathrm{X}$ & $\mathrm{X}$ & $\mathrm{X}$ & $\mathrm{X}$ \\
\hline & Adj. Signal & & & & & $\mathrm{X}$ & \\
\hline & Cross Traffic & & & & & & \\
\hline & Opp. Int. Corner & & $\mathrm{X}$ & & & & $\mathrm{X}$ \\
\hline & Path of Travel & & $\mathrm{X}$ & $\mathrm{X}$ & $\mathrm{X}$ & & $\mathrm{X}$ \\
\hline \multirow{6}{*}{9} & PPLT Signal & $\mathrm{X}$ & & $\mathrm{X}$ & $\mathrm{X}$ & $\mathrm{X}$ & $\mathrm{X}$ \\
\hline & Opp. Vehicles & $\mathrm{X}$ & $\mathrm{X}$ & $\mathrm{X}$ & $\mathrm{X}$ & $\mathrm{X}$ & $\mathrm{X}$ \\
\hline & Adj. Signal & & & & & $\mathrm{X}$ & \\
\hline & Cross Traffic & & $\mathrm{X}$ & & & $\mathrm{X}$ & $\mathrm{X}$ \\
\hline & Opp. Int. Corner & $\mathrm{X}$ & $\mathrm{X}$ & & $\mathrm{X}$ & & \\
\hline & Path of Travel & & $\mathrm{X}$ & $\mathrm{X}$ & & $\mathrm{X}$ & $\mathrm{X}$ \\
\hline \multirow{6}{*}{10} & PPLT Signal & $\mathrm{X}$ & $\mathrm{X}$ & $\mathrm{X}$ & $\mathrm{X}$ & $\mathrm{X}$ & $\mathrm{X}$ \\
\hline & Opp. Vehicles & $\mathrm{X}$ & $\mathrm{X}$ & $\mathrm{X}$ & $\mathrm{X}$ & $\mathrm{X}$ & $\mathrm{X}$ \\
\hline & Adj. Signal & & & & & & \\
\hline & Cross Traffic & & & & & & \\
\hline & Opp. Int. Corner & & & & & & \\
\hline & Path of Travel & & $\mathrm{X}$ & & $\mathrm{X}$ & & $\mathrm{X}$ \\
\hline \multirow{6}{*}{11} & PPLT Signal & $\mathrm{X}$ & $\mathrm{X}$ & $\mathrm{X}$ & $\mathrm{X}$ & $\mathrm{X}$ & $\mathrm{X}$ \\
\hline & Opp. Vehicles & $\mathrm{X}$ & $\mathrm{X}$ & $\mathrm{X}$ & $\mathrm{X}$ & $\mathrm{X}$ & $\mathrm{X}$ \\
\hline & Adj. Signal & & & $\mathrm{X}$ & & $\mathrm{X}$ & \\
\hline & Cross Traffic & & & & & & \\
\hline & Opp. Int. Corner & & & & & & \\
\hline & Path of Travel & $\mathrm{X}$ & $\mathrm{X}$ & $\mathrm{X}$ & $\mathrm{X}$ & $\mathrm{X}$ & $\mathrm{X}$ \\
\hline \multirow{6}{*}{$\begin{array}{c}\text { Total } \\
\text { for all } \\
11 \\
\text { Drivers }\end{array}$} & PPLT Signal & 11 & 10 & 11 & 11 & 11 & 11 \\
\hline & Opp. Vehicles & 11 & 11 & 11 & 11 & 11 & 11 \\
\hline & Adj. Signal & 2 & 2 & 2 & 3 & 6 & 1 \\
\hline & Cross Traffic & 0 & 3 & 0 & 0 & 1 & 4 \\
\hline & Opp. Int. Corner & 1 & 2 & 0 & 3 & 0 & 3 \\
\hline & Path of Travel & 5 & 10 & 4 & 7 & 3 & 10 \\
\hline TOTAL & $\begin{array}{c}\text { Cues used at } \\
\text { least once }\end{array}$ & 30 & 38 & 28 & 35 & 32 & 40 \\
\hline
\end{tabular}

As shown in Table 1, drivers used more total cues when no opposing traffic was present. Specifically, in the absence of opposing traffic, drivers fixated on a wider array of cues. When opposing traffic was present, drivers spent a majority of time focused on that and would use this as a base point from which they would glance at other sources. Overall, drivers looked at least once at the PPLT signal display and the opposing traffic stream. The next most prevalent fixation 
was drivers locating the path of travel before initiating the left-turn movement, and this event was more likely when opposing traffic was not present. Drivers tended to scan intersections from right to left, after initially locating the PPLT signal display and opposing traffic. Drivers who scanned more than once, tended to scan from right to left, then would relocate all the way back to the right after completing the first scan.

The information observed with the eye tracker is consistent with what drivers indicated in a follow-up static evaluation. Recall that, to complete the static format, drivers were positioned in front of the experimental scenarios and asked about the cues they used to make their left turn decisions. All drivers indicated that they based their decisions on the PPLT signal display, and that they looked at the opposing traffic and PPLT signal while waiting to complete the left-turn.

\section{CONCLUSIONS}

Although the study was completed using a limited number of subjects, consistent scan patterns among drivers completing left-turn maneuvers were found to exist. Furthermore, the application of simulator and eye tracking technology are well suited for this type of analysis. With respect to the permissive left-turn driving process, the following conclusions were generated:

- Evidence suggests 90 percent of drivers first look for the PPLT signal display, then focus on opposing traffic when it is present.

- Drivers tend to remain focused on the opposing traffic while waiting to complete a permissive left-turn, with periodic glances at other sources of information.

- In the absence of opposing vehicles, drivers were more likely to seek out additional cues. Furthermore, drivers scanning multiple sources at the intersection tended to scan from the right side of the intersection to the left, before resetting to the right and scanning again.

- There also is evidence to suggest that individual drivers use consistent scan patterns at similar types of intersections.

Further research on this topic is required to quantify the actual fixation times and identify the most significant sources of left-turn decision data. This research has the potential to lead to safety and operational improvements at signalized intersections by emphasizing this most critical information to the driver.

\section{ACKNOWLEDGMENTS}

The UMass simulator used in this research was established, in part, by a grant from the National Science Foundation (SBR-9413733) Engineering Infrastructure Program to Donald L. Fisher.

\section{REFERENCES}

Brehmer, C. L., Kacir, K. C., Noyce, D. A., M. P. Manser. (2003). Evaluation of Traffic Signal Displays for Protected/Permissive Left Turn Control. NCHRP Report 493. Washington DC: Transportation Research Board. 
Knodler, Michael A. Jr., David A. Noyce, Kent C. Kacir and Christopher L. Brehmer. (2005). An Evaluation of Traffic Signal Displays for Protected-Permissive Left-Turn Control Using Driving Simulator Technology. Journal of Transportation Engineering, 131(4), American Society of Civil Engineers, pp. 270-278.

Noyce, David .A. (1998). Development of a Uniform Traffic Signal Display for Protected/Permitted Left-Turn Signal Displays. Ph.D. Dissertation, Texas A\&M University, College Station, TX. 